\title{
$N$-(3,5-Dihydroxybenzoyl)-6-hydroxytryptamine as a Novel Human Tyrosinase Inhibitor That Inactivates the Enzyme in Cooperation with L-3,4-Dihydroxyphenylalanine
}

\author{
Yoshimitsu YAMAZAKI* and Yasuhiro KaWANO \\ Biomedical Research Institute, National Institute of Advanced Industrial Science and Technology; 1-1-1 Higashi, \\ Tsukuba, Ibaraki 305-8566, Japan. \\ Received July 2, 2010; accepted August 30, 2010; published online September 3, 2010
}

$\mathrm{N}$-(3,5-Dihydroxybenzoyl)-6-hydroxytryptamine (2) was a novel inhibitor of L-3,4-dihydroxyphenylalanine (DOPA) oxidase activity of human HMV-II melanoma tyrosinase. The $\mathrm{IC}_{50}$ values for 2 and three reference compounds, $N$-(3,5-dihydroxybenzoyl)serotonin, 6-hydroxyindole, and kojic acid, were 9.1, 842, 22, and $310 \mu \mathrm{M}$, respectively, indicating that the 6-hydroxyindole moiety was more effective than 5-hydroxyindole as the pharmacophore of polyphenolic tyrosinase inhibitors and that the inhibitory activity of 6-hydroxyindole was strengthened by the link with a resorcinol group. Furthermore, compound 2 exhibited a unique property of inactivating the human tyrosinase in the presence of low concentrations of DOPA. This inactivation was attenuated by high concentrations of DOPA and for the most part was irreversible as confirmed by activity stain in native polyacrylamide gel electrophoresis and by removal of 2 and DOPA using gel permeation chromatography. Tyrosinase is the enzyme that oxidizes tyrosine to DOPA and further oxidizes DOPA to the melanin precursor dopaquinone. A compound such as 2 that inactivates the enzyme in the presence of a small amount of DOPA is therefore attractive as a new type of tyrosinase inhibitor. Unfortunately, 2 hardly suppressed the melanogenesis in melanoma cell culture. However, the above strong inhibitory activity and the unique property in the combination with DOPA suggest that this compound is a useful lead in designing new antimelanogenic agents.

Key words tyrosinase; inhibitor; human; L-3,4-dihydroxyphenylalanine; hydroxyindole; phenolic

Inhibitors of tyrosinase (EC 1.14.18.1) are potentially applicable to skin lightening agents. ${ }^{1)}$ A major class of tyrosinase inhibitors is phenolic compounds structurally analogous to the substrates, L-tyrosine and L-3,4-dihydroxyphenylalanine (DOPA). ${ }^{1-4)}$ Recently, we found that introduction of a dihydroxyphenyl group into serotonin (that is, a 5-hydroxyindole derivative) improved its tyrosinase inhibitory activity. ${ }^{5}$ The succeeding study with positional isomers of hydroxyindoles revealed that 6-hydroxyindole (1) was more potent than 5-hydroxyindole as an inhibitor of human HMV-II melanoma tyrosinase. ${ }^{6}$ The present study was aimed at evaluating the link of 6-hydroxyindole and a dihydroxyphenyl moiety as the design of tyrosinase inhibitors. Thus, the synthesized compound, $N$-(3,5-dihydroxybenzoyl)-6-hydroxytryptamine (2), inhibited HMV-II tyrosinase more strongly than 6-hydroxyindole (1) and related compounds (Fig. 1) and, moreover, exhibited a unique property of inactivating the enzyme in the

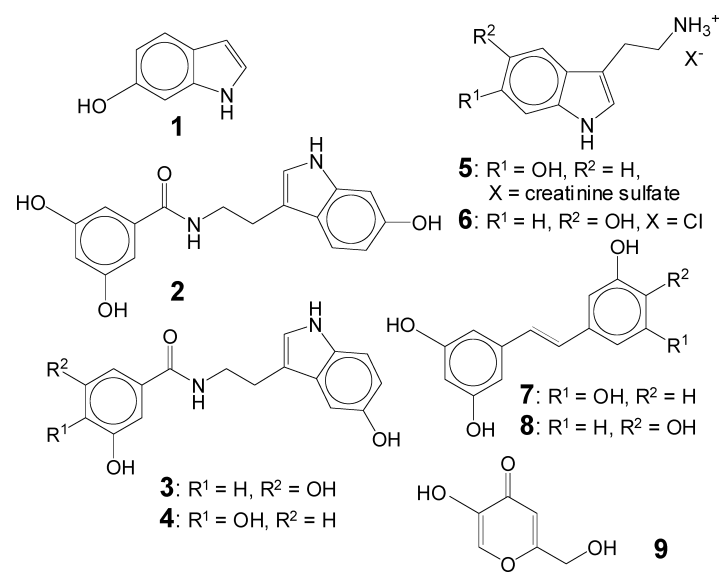

Fig. 1. Chemical Structures of the Compounds presence of the substrate DOPA at very low concentrations.

\section{Results and Discussion}

The compound 2 was synthesized by coupling of 6-benzyloxytryptamine hemisulfate (10) with 3,5-dihydroxybenzoic acid (11) using dicyclohexylcarbodiimide (DCC $)^{7}$ followed by catalytic hydrogenation to remove the benzyl group. Although the intrinsic substrate, DOPA, contains an orthodiphenol (catechol) group, meta-diphenolic acid $\mathbf{1 1}$ was selected because the catechol group was not necessarily superior to the meta-diphenol in inhibiting tyrosinase as judged from the facts that 3,5,2',4'-tetrahydroxybenzamide was the strongest tyrosinase inhibitor among many hydroxy-substituted $N$-benzylbenzamides ${ }^{8)} N$-(2,4-dihydroxybenzoyl)serotonin was a stronger inhibitor than $N$-(3,4-dihydroxybenzoyl)serotonin, ${ }^{5)}$ and oxyresveratrol (7) was a much stronger inhibitor than piceatannol (8) (Table 1). $N$-(3,5-Dihydroxybenzoyl)serotonin (3) was also synthesized by DCC-mediated coupling of serotonin hydrochloride with $\mathbf{1 1}$ for comparison between 6- and 5-hydroxyindole moieties. The inhibitory activities of these compounds together with five related and reference compounds [6-hydroxyindole (1), $N$ - (3,4dihydroxybenzoyl)serotonin (4), ${ }^{5)}$ 6-hydroxytryptamine creatinine sulfate salt (5), serotonin hydrochloride (6), and kojic acid (9)] were tested for the catecholase activity of HMV-II melanoma tyrosinase. The results are summarized in Table 1. The $\mathrm{IC}_{50}$ value for compound 2 against HMV-II tyrosinase was less than one half of the value for 6-hydroxyindole (1), showing that the introduction of the dihydroxyphenyl moiety enhanced the inhibitory activity of $\mathbf{1}$. The compound $\mathbf{2}$ was the second strongest inhibitor of HMV-II tyrosinase in Table 1 , but the $\mathrm{IC}_{50}$ was only $1.5 \mu \mathrm{M}$ higher than that for the strongest inhibitor, oxyresveratrol (7). The $\mathrm{IC}_{50}$ for $\mathbf{2}$ against HMV-II tyrosinase was markedly smaller $(1 / 90-1 / 40)$ than 
Table 1. Inhibitory Activity of the Compounds for Tyrosinase from Human HMV-II Melanoma Cells ${ }^{a}$

\begin{tabular}{lcc}
\hline \hline \multicolumn{1}{c}{ Compound } & $\begin{array}{c}\mathrm{IC}_{50} \\
(\mu \mathrm{M})\end{array}$ & $\begin{array}{c}\% \text { inhibition } \\
\left.\text { at } 100 \mu \mathrm{M}^{c}\right)\end{array}$ \\
\hline 6-Hydroxyindole (1) & $22 \pm 1$ & $79 \pm 1$ \\
$N$-(3,5-Dihydroxybenzoyl)-6- & $9.1 \pm 0.3$ & $94 \pm 1$ \\
$\quad$ hydroxytryptamine (2) & $842 \pm 40$ & $17 \pm 7$ \\
$N$-(3,5-Dihydroxybenzoyl)serotonin (3) & $343 \pm 29$ & $27 \pm 5$ \\
$N$-(3,4-Dihydroxybenzoyl)serotonin (4) & $12 \pm 1^{d)}$ & $77 \pm 4^{d, e)}$ \\
6-Hydroxytryptamine creatinine sulfate (5) & $>1000$ & $5 \pm 3$ \\
Serotonin hydrochloride (6) & $7.6 \pm 0.3$ & 98 \\
Oxyresveratrol (7) & $>300$ & $10 \pm 3$ \\
Piceatannol (8) & $310 \pm 40$ & $27 \pm 1$ \\
Kojic acid (9) & & \\
\hline
\end{tabular}

a) Values are means \pm S.D. (standard deviation), $n=3$. b) $\mathbf{5}$ was dissolved in water as the sample solution $(0.1-10 \mathrm{~mm})$ and water was used as the control. Creatinine $(100 \mu \mathrm{M})$ was confirmed to be inactive in this inhibition assay. c) Calculated by subtracting the relative activity ( $\%$ of control) from $100 . \quad d) n=2$. e) At $30 \mu \mathrm{m}$.

those for the corresponding 5-hydroxyindole derivatives 3 and 4. 6-Hydroxytryptamine creatinine salt (5) also showed a very small $\mathrm{IC}_{50}$ as compared to serotonin hydrochloride (6). These facts confirm that the 6-hydroxy group in indole is more effective than the 5-hydroxy group for the tyrosinase inhibition. Many kinds of tyrosinase inhibitors have been developed, but their inhibitory activities were mostly assayed with mushroom and mouse B16 melanoma tyrosinase. ${ }^{1)}$ However, the activity of inhibitors against mushroom tyrosinase is often very different from that against mammalian tyrosinase, ${ }^{5,6)}$ so if the inhibitor is to be applied to human skin agents, it is beneficial to test them with human tyrosinase. Though few data are presently available concerning human tyrosinase, the $\mathrm{IC}_{50}$ for $\mathbf{2}$ against HMV-II tyrosinase belongs to the smallest group among the reported $\mathrm{IC}_{50}$ for arbutin,, , 10) aloesin, ${ }^{10)}(+)$-imperanene, ${ }^{11)}$ and kinobeon. ${ }^{12)}$ Also in Table 1 , the $\mathrm{IC}_{50}$ for $\mathbf{2}$ is one thirty-fourth that for kojic acid (9), a standard tyrosinase inhibitor, and as small as that for oxyresveratrol (7), the active ingredient in the whitening cosmetics from Morus alba. ${ }^{13)}$ Thus, the inhibitory activity of $\mathbf{2}$ against the human tyrosinase is higher than or comparable to those of the known inhibitors.

The Lineweaver-Burk plots obtained with different concentrations of $\mathbf{2}$ for HMV-II tyrosinase activity cross at a point slightly to the left of the $Y$-axis, indicating that $\mathbf{2}$ is a mixed type inhibitor with respect to DOPA (Fig. 2). The apparent Michaelis constant $\left(K_{\mathrm{m}}\right)$ was $1.1 \mathrm{~mm}$ and replots of the slope and $Y$-intercept of the lines in Fig. 2 vs. concentration of 2 gave the inhibitor constants $K_{\mathrm{i}}=1.7 \mu \mathrm{M}$ for EnzymeInhibitor complex and $K_{\mathrm{i}}^{\prime}=53 \mu \mathrm{M}$ for Enzyme-SubstrateInhibitor complex, respectively. ${ }^{14)}$ Although the simple Michaelis-Menten kinetics is not properly applied here because of the enzyme inactivation induced by $\mathbf{2}$ and DOPA (see the later section), it is most likely that compound $\mathbf{2}$ primarily competes for the enzyme active site with DOPA. Tyrosinase contains a binuclear copper complex in the active center for the substrate binding and oxidation. Since the two resorcinol derivatives $\mathbf{2}$ and $\mathbf{3}$ showed the very different inhibitory activities, $\mathbf{2}$ is bound to the copper center for the inhibition probably through 6-hydroxyindole moiety rather than the resorcinol moiety. In addition, HPLC analysis showed that the peak of $\mathbf{2}$ did not change after incubation with HMV-II tyrosinase for $1 \mathrm{~h}$, while DOPA diminished by

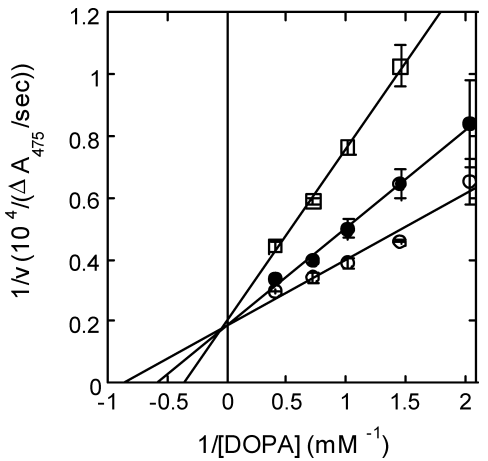

Fig. 2. Lineweaver-Burk Plots for DOPA Oxidation by HMV-II Tyrosinase in the Presence of Compound 2

Concentrations of 2: $0(\bigcirc), 1(\bullet)$, and $3 \mu \mathrm{M}(\square)$. Every point is the mean \pm S.D $(n=3)$. Plot lines are drawn by least linear regression.
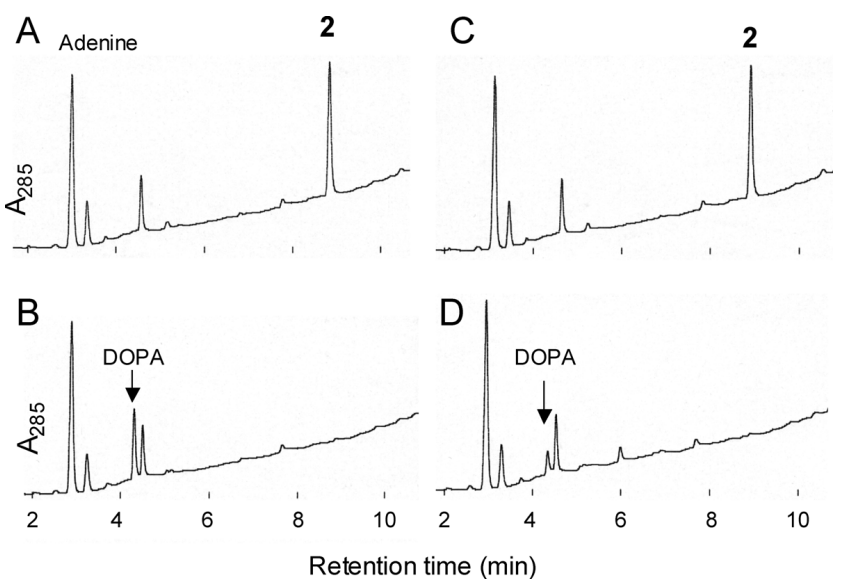

Fig. 3. HPLC Analysis

Chromatograms for the mixtures of tyrosinase and $10 \mu \mathrm{M} 2(\mathrm{~A}, \mathrm{C})$ or $10 \mu \mathrm{M}$ DOPA $(\mathrm{B}, \mathrm{D})$ before $(\mathrm{A}, \mathrm{B})$ and after incubation at $37^{\circ} \mathrm{C}$ for $1 \mathrm{~h}(\mathrm{C}, \mathrm{D})$

$71 \%$ under the same condition (Fig. 3). This result confirms that 2 is not a substrate of the tyrosinase under this experimental condition.

To study the inhibition mechanism in more detail, HMV-II tyrosinase was pretreated with compound 2 before assay with DOPA. The pretreatment mixtures were prepared without or with a small amount of DOPA to investigate the effect of 2 on the enzyme turning over in catalysis. Thus, HMV-II tyrosinase solutions containing 2 and/or DOPA, or none of them were incubated at $37^{\circ} \mathrm{C}$ for $1 \mathrm{~h}$ and then DOPA was added to the solutions to $2.5 \mathrm{~mm}$ (i.e., the concentration used in the standard assay). After standing at room temperature for $24 \mathrm{~h}$, the mixtures pretreated with 2 plus $10 \mu \mathrm{M}$ DOPA showed melanin formation as low as the control level (autoxidation of DOPA), while all mixtures pretreated with 2 alone became dark with much melanin (Fig. 4A). This pretreatment effect of an inhibitor plus DOPA was not found with compound 3 though its concentration was ten times that used for 2. In addition, 6-hydroxyindole (1) and oxyresveratrol (7) showed a similar combination effect with DOPA on the melanin suppression (data not shown). The tyrosinase activity itself decreased by the pretreatment with 2 plus DOPA and the activity loss increased with the preincubation time. When treated only with $\mathbf{2}$ or DOPA, the tyrosinase activity 

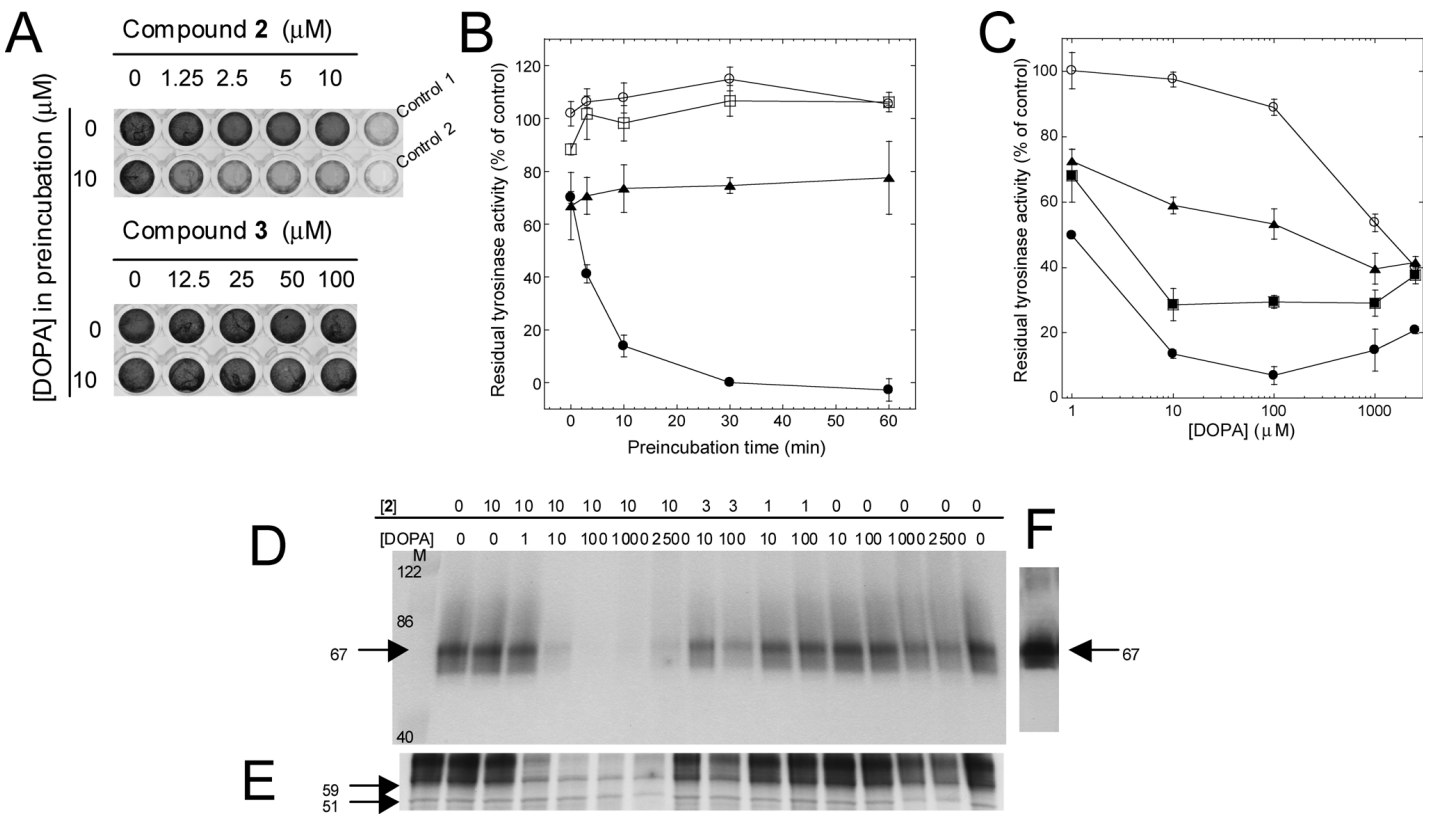

Fig. 4. Tyrosinase Inactivation by 2 in the Presence of Low Concentrations of DOPA

(A) Melanin formation by tyrosinase preincubated with $0-10 \mu \mathrm{M} 2$ or $0-100 \mu \mathrm{M} 3$ without or with $10 \mu \mathrm{M}$ DOPA for $1 \mathrm{~h}$. After the preincubation, DOPA was added to $2.5 \mathrm{mM}$ and then the plate was left at room temperature for $24 \mathrm{~h}$. Control 1 contained $50 \mathrm{~mm}$ phosphate buffer (pH 6.8 , without tyrosinase and the inhibitors) but received $2.5 \mathrm{~mm}$ DOPA. Control 2 contained and received the buffer only. The wells of preincubation with 5 or $10 \mu \mathrm{M} 2$ plus $10 \mu \mathrm{m}$ DOPA are as light as the well of control 1 , while those of preincubation with $\mathbf{2}$ alone or with $\mathbf{3}$ and/or DOPA are all dark, indicating that the simultaneous pretreatment with $\mathbf{2}$ and DOPA suppressed the melanin formation and that $\mathbf{3}$ was not effective in suppressing the melanin even with DOPA. (B) Effect of the length of preincubation time. Samples contained tyrosinase and $10 \mu \mathrm{M} 2$ plus $10 \mu \mathrm{M}$ DOPA $(\boldsymbol{\bullet}), 10 \mu \mathrm{M} 2$ alone $(\boldsymbol{\Delta})$, $10 \mu \mathrm{M}$ DOPA alone $(\square)$, or none of them $(\bigcirc)$. The preincubation time was $0,3,10,30$, and $60 \mathrm{~min}$. (C) Effect of the concentrations of DOPA and 2 in the preincubation for 10 min. Samples contained tyrosinase, $2[0(\mathrm{O}), 1(\boldsymbol{\Delta}), 3(\boldsymbol{\square})$, or $10 \mu \mathrm{M}(\boldsymbol{O})]$, and DOPA $(0,1,10,100,1000$, or $2500 \mu \mathrm{M})$. The vertical axis in B and C represents the residual enzyme activity expressed as $\%$ of control (without 2 and DOPA at time 0 ). Every point is the mean \pm S.D. $(n=3)$. (D) Tyrosinase activity staining after native PAGE for samples preincubated without or with 2 and/or DOPA. Their concentrations $(\mu \mathrm{M})$ are indicated on the top. M indicates molecular weight marker proteins (kDa). (E) Coomassie brilliant blue staining of the same gel as above. Bands of 59 or $51 \mathrm{kDa}$ serve as protein loading reference. (F) Western blot of tyrosinase electrophoresed under the same condition as above. Color prints of $\mathrm{D}$ and $\mathrm{E}$, see the Graphical Abstract.

slightly changed in the experimental period (Fig. 4B). The loss of tyrosinase activity was dependent on the dose of $\mathbf{2}$ and DOPA (Fig. 4C). The plots of the residual activities determined after preincubation for 10 min show that DOPA itself caused the decrease in tyrosinase activity at the high concentrations, but that the effect of DOPA was increased by the presence of $\mathbf{2}$. The maximum effect of DOPA was found at about $100 \mu \mathrm{M}$ in the combination with $10 \mu \mathrm{M} 2$. The entity of tyrosinase treated with $\mathbf{2}$ and DOPA was investigated by the method of activity stain in native polyacrylamide gel electrophoresis (PAGE). ${ }^{15)}$ The untreated tyrosinase gave the main activity band (colored red) at molecular weight of $67 \mathrm{kDa}$ (lit. ${ }^{16)} 62610 \mathrm{Da}$ ), whose migration was consistent with that of the immunologically stained tyrosinase band (Figs. 4D, F; see also the color print in Graphical Abstract). The activity band for the samples treated with $10 \mu \mathrm{M} 2$ plus 10 or $2500 \mu \mathrm{M}$ DOPA was faint and it did not appear for the samples treated with $10 \mu \mathrm{M} 2$ plus 100 or $1000 \mu \mathrm{M}$ DOPA. The activity band was also lighter for the samples treated with 1000 or $2500 \mu \mathrm{M}$ DOPA alone than those for the samples treated with $0-100 \mu \mathrm{M}$ DOPA. This coloration is nearly parallel to the enzyme activity shown in Fig. 4C, suggesting that the activity decrease by $\mathbf{2}$ and DOPA is due to disappearance of the main tyrosinase activity.

The combination effect of $\mathbf{2}$ with DOPA was further studied by separating the pretreated enzyme from $\mathbf{2}$ and DOPA by gel permeation chromatography (GPC). Samples containing tyrosinase without or with $10 \mu \mathrm{M} 2$ and/or $10 \mu \mathrm{M}$ DOPA were incubated at $37^{\circ} \mathrm{C}$ for $1 \mathrm{~h}$ and then directly assayed with $2.5 \mathrm{~mm}$ DOPA (Fig. 5A) or assayed with the protein fractions after passing through a Sephadex ${ }^{\circledR}$ G-50 column (Fig. 5B). The initial velocity ( $\%$ of the control) for the sample pretreated only with 2 recovered from 42 to $78 \%$ by the GPC treatment ( $c f$. plots $\mathrm{c}$ and $\mathrm{c}^{\prime}$ ), but that for the sample pretreated with 2 plus DOPA recovered from $0 \%$ (plot d) to only $9 \%$ (plot $\mathrm{d}^{\prime}$ ). This enzyme activity did not significantly increase when the same sample (the column eluate) was left at room temperature for $6 \mathrm{~h}$ before initiating the assay (plot $\mathrm{d}^{\prime \prime}$ ).

The most interesting property of compound $\mathbf{2}$ is that the inhibition of HMV-II tyrosinase by $\mathbf{2}$ is greatly strengthened by the presence of low concentrations of DOPA. Since this inhibition remains long after the condition is altered by the addition of high concentrations of DOPA, it might be reasonable to conclude that the enzyme is inactivated by the treatment with 2 plus DOPA. The disappearance of activity stain in PAGE (Fig. 4D) and the limited recovery of activity after GPC separation (Fig. 5B) imply that this inactivation is mostly irreversible. Tyrosinase is known to be inactivated during the oxidation of DOPA ${ }^{17,18)}$ and several phenolic substrates. ${ }^{19-21)}$ This type of inactivation is called suicide inactivation, whose mechanism has been discussed for many years. ${ }^{17-23)}$ For example, a two-electron transfer from the substrate to the active center $\mathrm{Cu}^{2+}$ ion leading to its liberation as a $\mathrm{Cu}^{0}$ atom was proposed as the mechanism for inactivation of tyrosinase in the enzymatic oxidation of resorcinol. ${ }^{21)}$ Compound $\mathbf{2}$ has a resorcinol moiety, but this is probably not the cause of the present inactivation, since another resorcinol derivative $\mathbf{3}$ did not suppress the melanin formation (Fig. 4A). The above-mentioned electron transfer might be possible from the 6-hydroxyindole moiety with pro- 

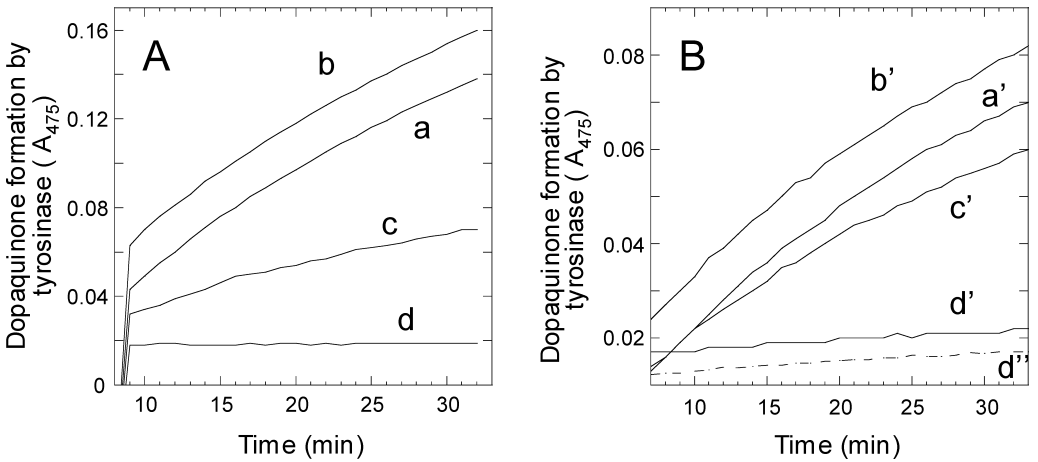

Fig. 5. Tyrosinase Activity Pretreated with $\mathbf{2}$ and/or DOPA and That Recovered from the Mixtures by GPC

(A) Monitor of DOPA oxidation by tyrosinase $1 \mathrm{~h}$ preincubated with $10 \mu \mathrm{M} 2$ and $10 \mu \mathrm{M}$ DOPA (plot d), $10 \mu \mathrm{M} 2$ alone (c), $10 \mu \mathrm{M}$ DOPA alone (b), or none of them (a). (B) Monitor of DOPA oxidation by tyrosinase in the protein fractions from GPC of the same preincubated samples as above. Plot a', $\mathrm{b}^{\prime}, \mathrm{c}^{\prime}, \mathrm{d}^{\prime}$, and $\mathrm{d}^{\prime \prime}$ correspond to plot a, b, c, d, and d, respectively. Plot d" was recorded after the column eluate was left at room temperature for $6 \mathrm{~h}$. The total activities indicated by plot a and plot a' were almost equal as calculated with the volumes of assay mixture and sample solution.

duction of a conjugated iminoketone, but presently we have no evidence for it. Although DOPA may act as the suicide substrate in the present phenomenon, its effective concentration (around $100 \mu \mathrm{M}$ ) is considerably low as compared to those $(0.25-10 \mathrm{~mm})$ used for suicide inactivation under aerobic conditions. ${ }^{17,18)}$ The effectiveness of DOPA at such a low concentration implies a possibility that $\mathbf{2}$ enhances the suicide inactivation by DOPA, for instance, through conformational change of the enzyme protein by binding. However, this mechanism does not explain the fact that there was the optimum concentration for DOPA in the combination effect with 2 (Fig. 4C). One possible interpretation of this phenomenon is that a specific binding of $\mathbf{2}$ to $o x y$ - or red-tyrosinase might result in the inactivation of the enzyme. The copper complex in tyrosinase is cycled among met-, oxy-, and red(or deoxy-)state in the catalytic process. ${ }^{1)}$ The oxy- or red-tyrosinase must be generated in the enzymatic reaction with DOPA, since the native (resting) tyrosinase is mostly in the met-state. ${ }^{23)}$ The proportion of the $o x y$ - or red-tyrosinase is established by the relative concentrations of DOPA, inhibitor, $\mathrm{O}_{2}$, and the enzyme. If DOPA is in excess over $\mathbf{2}$, the enzyme proceeds to the normal reaction step to avoid complexing with 2. This would explain the need for the limited concentration of DOPA for the present inactivation by 2 . On the other hand, the suicide inactivation by DOPA should be irreversible as expected from the zero-valent copper formation mechanism. ${ }^{19,21)}$ The GPC experiment indicated that the removal of $\mathbf{2}$ and DOPA from the pretreated enzyme restored only $9 \%$ of the control activity and this recovery increased no further during the 6-h standing (Fig. 5B). This fact suggests that the major part of HMV-II tyrosinase is irreversibly inactivated by the treatment with 2 plus DOPA, while the minor part is reversibly inactivated. The coexistence of two kinds of inactivation might be due to a heterogeneity of the tyrosinase. Now, it is not clear whether 2 causes the present inactivation by its permanent binding to the enzyme, or $\mathbf{2}$ merely promotes the DOPA-induced suicide inactivation, or $\mathbf{2}$ itself serves as a suicide substrate. Some irreversible inhibitors were reported for mushroom tyrosinase, ${ }^{24,25)}$ but few are known for human tyrosinase. Furthermore, the combination effect of inhibitors with DOPA has not been reported for any tyrosinase.

Tyrosinase is the enzyme that oxidizes tyrosine to DOPA and further oxidizes DOPA to the melanin precursor dopaquinone. A compound such as $\mathbf{2}$ that inactivates the enzyme in the presence of a small amount of DOPA is therefore attractive as a new type of tyrosinase inhibitor. Unfortunately, compound $\mathbf{2}$ was rather inactive in suppressing the melanogenesis in cultured HMV-II cells. The melanin formation in these cells was not significantly suppressed by 3 $20 \mu_{\mathrm{M} 2}$, while $10-30 \mu_{\mathrm{M}} 2$ decreased the cell viability (data not shown). These problems must be solved by further modification of the chemical structure. However, the above strong inhibitory activity and the unique property in the combination with DOPA suggest that this compound is a useful lead in designing new antimelanogenic agents. The mechanism of the present inactivation is to be studied through detailed kinetic analysis using purified HMV-II tyrosinase in future.

\section{Experimental}

Materials 6-Hydroxytryptamine creatinine sulfate (5) and 2-(6-benzyloxyindolyl)ethylamine hemisulfate (10) were purchased from Toronto Research Chemicals Inc. (North York, ON, Canada), 6-hydroxyindole (1), piceatannol (8), and serotonin hydrochloride (6) were from Wako Pure Chemicals Inc. (Osaka, Japan), kojic acid (9) and 3,5-dihydroxybenzoic acid (11) were from Tokyo Chemical Industries Ltd. (Tokyo, Japan), and oxyresveratrol (7) was from Hangzhou Great-Forest Biomedical Ltd. (Hangzhou, P. R. China).

Synthesis $N$-(3,5-Dihydroxybenzoyl)-6-hydroxytryptamine (2) was synthesized by the DCC method. $\left.{ }^{7}\right)$ The amine salt $\mathbf{1 0}(100 \mathrm{mg})$ was suspended in $5 \mathrm{ml}$ dimethylformamide (DMF) containing $2 \mathrm{ml}$ pyridine and mixed with a solution of $100 \mathrm{mg}$ 3,5-dihydroxybenzoic acid (11) and $100 \mathrm{mg}$ DCC in $0.5 \mathrm{ml}$ DMF. The mixture was stirred at room temperature for $1 \mathrm{~h}$. The insoluble material was collected by centrifugation, suspended in $1 \mathrm{ml}$ dimethylsulfoxide containing $0.2 \mathrm{ml}$ pyridine, and supplemented with $200 \mathrm{mg} 11$ and $200 \mathrm{mg}$ DCC. To the supernatant from the above centrifugation, $200 \mathrm{mg} 11$ and $400 \mathrm{mg}$ DCC were added. After stirring at room temperature overnight, the two mixtures were filtered and the filtrates were concentrated by a rotary evaporator. The residues were respectively dissolved in $30 \mathrm{ml}$ ethyl acetate, and washed successively with $10 \%$ citric acid, $10 \% \mathrm{NaHCO}_{3}$, and saturated $\mathrm{NaCl}$ in water. Finally, the ethyl acetate solutions were combined, dried over $\mathrm{Na}_{2} \mathrm{SO}_{4}$, concentrated by an evaporator, and applied to a silica gel column. The eluate with ethyl acetate was dissolved in $4 \mathrm{ml}$ ethanol containing $0.2 \mathrm{ml}$ acetic acid, and hydrogenated over $30 \mathrm{mg} \mathrm{Pd} / \mathrm{C}$ at an atmospheric pressure for $4 \mathrm{~h}$. The catalyst was filtered off and the filtrate was concentrated to give a residue, which was purified by silica gel column chromatography. The main product (2) was eluted with ethyl acetate and crystallized from ethyl acetate and benzene as fine needles ( $34 \mathrm{mg}, 34 \%$ yield), dec. $213-217^{\circ} \mathrm{C}$, Anal. Calcd for $\mathrm{C}_{17} \mathrm{H}_{16} \mathrm{~N}_{2} \mathrm{O}_{4} \cdot{ }^{1} / 2 \mathrm{H}_{2} \mathrm{O}: \mathrm{C}, 63.54 ; \mathrm{H}, 5.33 ; \mathrm{N}, 8.72 \%$. Found: $\mathrm{C}$, 63.37; H, 5.31; N, 8.46\%; FAB-MS $m / z 313.1197\left([\mathrm{M}+\mathrm{H}]^{+}\right)(\mathrm{Calcd}$ $\left.\mathrm{C}_{17} \mathrm{H}_{17} \mathrm{~N}_{2} \mathrm{O}_{4}=313.1187\right)$; and ${ }^{1} \mathrm{H}-\mathrm{NMR}\left(270 \mathrm{MHz}\right.$, acetone- $\left.d_{6}\right) \delta: 2.99(2 \mathrm{H}$, $\left.\mathrm{t}, J=7 \mathrm{~Hz}, \mathrm{CH}_{2}\right), 3.64\left(2 \mathrm{H}, \mathrm{m}, \mathrm{CH}_{2} \mathrm{~N}\right), 6.47(1 \mathrm{H}, \mathrm{t}, J=2 \mathrm{~Hz}, \mathrm{H}-4), 6.64(1 \mathrm{H}$, 
dd, $J=8$ and $\left.2 \mathrm{~Hz}, \mathrm{H}-5^{\prime}\right), 6.82\left(1 \mathrm{H}, \mathrm{d}, J=2 \mathrm{~Hz}, \mathrm{H}-7^{\prime}\right), 6.84(2 \mathrm{H}, \mathrm{d}, J=2 \mathrm{~Hz}$ H-2,5), $6.99\left(1 \mathrm{H}, \mathrm{m}, \mathrm{H}-2^{\prime}\right), 7.43\left(1 \mathrm{H}, \mathrm{d}, J=8 \mathrm{~Hz}, \mathrm{H}-4^{\prime}\right), 7.56(1 \mathrm{H}$, br s $\mathrm{NHCO}), 7.82(1 \mathrm{H}$, br s, OH), $8.41(2 \mathrm{H}$, br s, $\mathrm{OH} \times 2)$, and $9.64(1 \mathrm{H}$, br s, $\mathrm{H}-$ $\left.1^{\prime}\right)$.

$N$-(3,5-Dihydroxybenzoyl)serotonin (3) was similarly prepared from 6 and 11, crystalline solid, $94 \mathrm{mg}(64 \%$ yield $), \mathrm{mp} 113-117^{\circ} \mathrm{C}$ and dec. 215 $218^{\circ} \mathrm{C}$ (with multiple phase transitions), FAB-MS $m / z 313\left([\mathrm{M}+\mathrm{H}]^{+}\right)$ (Calcd $\left.\mathrm{C}_{17} \mathrm{H}_{16} \mathrm{~N}_{2} \mathrm{O}_{4}=312\right)$. ${ }^{1} \mathrm{H}-\mathrm{NMR}\left(270 \mathrm{MHz}\right.$, acetone- $\left.d_{6}\right) \delta: 2.98(2 \mathrm{H}, \mathrm{t}$ $\left.J=7 \mathrm{~Hz}, \mathrm{CH}_{2}\right), 3.66\left(2 \mathrm{H}, \mathrm{m}, \mathrm{CH}_{2} \mathrm{~N}\right), 6.51(1 \mathrm{H}, \mathrm{t}, J=2 \mathrm{~Hz}, \mathrm{H}-4), 6.71(1 \mathrm{H}$ dd, $J=8$ and $\left.2 \mathrm{~Hz}, \mathrm{H}-6^{\prime}\right), 6.84(2 \mathrm{H}, \mathrm{d}, J=2 \mathrm{~Hz}, \mathrm{H}-2,5), 7.06(1 \mathrm{H}, \mathrm{d}, J=2 \mathrm{~Hz}$, H-4'), $7.10\left(1 \mathrm{H}\right.$, br s, H-2'), $7.46\left(1 \mathrm{H}, \mathrm{d}, J=8 \mathrm{~Hz}, \mathrm{H}-7^{\prime}\right), 7.72(1 \mathrm{H}$, br s, $\mathrm{NHCO}), 7.98\left(1 \mathrm{H}\right.$, br s, OH), $8.33\left(1 \mathrm{H}\right.$, br s, OH), and $9.75\left(1 \mathrm{H}\right.$, br s, H- $\left.{ }^{\prime}\right)$ $\mathrm{N}$-(3,4-Dihydroxybenzoyl)serotonin (4) was synthesized in the previous work. $^{5)}$

Tyrosinase Assay Human HMV-II melanoma cells (Dai-Nippon-Sumitomo Pharmaceuticals Inc., Osaka, Japan) were grown in RPMI-1640 medium containing $15 \%$ fetal bovine serum. Tyrosinase was extracted from cells with a lysis buffer containing $150 \mathrm{~mm} \mathrm{NaCl}, 1 \mathrm{~mm}$ ethylenediaminetetraacetic acid, $1 \mathrm{~mm}$ phenylmethylsulfonyl fluoride, $1 \%$ polyoxyethylene $(9)$ octylphenyl ether (NP-40), $0.1 \% \mathrm{Na}$ dodecylsulfate, and $0.1 \% \mathrm{Na}$ deoxycholate in $10 \mathrm{~mm}$ Tris $/ \mathrm{HCl}$ buffer $(\mathrm{pH} 7.4)$ by sonication at $4{ }^{\circ} \mathrm{C}$. After removing the cell debris by centrifugation $(15000 \mathrm{rpm}, 10 \mathrm{~min})$, the supernatant was used as the tyrosinase source. Protein was determined by the bicinchoninic acid method with bovine serum albumin as standard. The tyrosinase activity was assayed with DOPA as the substrate. ${ }^{5)}$ Briefly, assay solutions were prepared by mixing $0.94 \mathrm{ml} 50 \mathrm{~mm}$ phosphate buffer ( $\mathrm{pH} 6.8$ ) containing $2.6 \mathrm{~mm}$ DOPA and $10 \mu \mathrm{l}$ ethanol containing $0-30 \mathrm{~mm}$ test compound, unless otherwise stated. The reaction was started by adding $50 \mu \mathrm{l}$ en zyme solutions adequately diluted with the lysis buffer to the substrate solutions prewarmed to $37^{\circ} \mathrm{C}$, and the dopaquinone formation during incubation for $5 \mathrm{~min}$ was determined by light absorption at $475 \mathrm{~nm}\left(\varepsilon=3700 \mathrm{M}^{-1} \mathrm{~cm}^{-1}\right)$. Usually, $2.5-3 \mathrm{mU}$ enzyme ${ }^{5)}$ was applied per assay.

HPLC Analysis Samples containing $2.5 \mathrm{mU} / \mathrm{ml}$ tyrosinase, $10 \mu \mathrm{M} 2$ or $10 \mu \mathrm{M}$ DOPA, and $10 \mu \mathrm{M}$ adenine (as an internal standard) in $50 \mathrm{~mm}$ phosphate buffer $(\mathrm{pH} 6.8)$ were prepared and $0.45 \mathrm{ml}$ of each sample was mixed with $50 \mu 13 \%$ trifluoroacetic acid (TFA) immediately or after incubation at $37{ }^{\circ} \mathrm{C}$ for $1 \mathrm{~h}$. After removing the precipitate by centrifugation, the solutions were subjected to HPLC with a Capcell Pak C18 column, $4.6 \times 150 \mathrm{~mm}$ (Shiseido Co., Ltd., Tokyo, Japan). Elution was performed with a 10-min linear gradient from $0.1 \%$ TFA to $70 \%$ methanol containing $0.1 \%$ TFA at a flow rate of $1.5 \mathrm{ml} / \mathrm{min}$ and peak was monitored by UV absorption at $285 \mathrm{~nm}$. Retention times were $3.1,4.5$, and 8.9 min for adenine, DOPA, and 2, respectively.

Preincubation Experiments In these experiments, samples and DOPA solutions were prepared in $50 \mathrm{~mm}$ phosphate buffer $(\mathrm{pH} 6.8)$. Compound 2 or 3 was added as $1-10 \mu$ l ethanol solutions so as to keep the total ethanol concentration below $2 \%$, unless otherwise stated. (1) Samples (134 $\mu$ l each) containing $4.8 \mathrm{mU} / \mathrm{ml}$ tyrosinase and $0-10 \mu \mathrm{M} 2$ or $0-100 \mu \mathrm{M} 3$ without or with $10 \mu \mathrm{M}$ DOPA were prepared in a 96-well plate, preincubated at $37^{\circ} \mathrm{C}$ for $1 \mathrm{~h}$, and then $5.3 \mathrm{~mm}$ DOPA solution $(120 \mu \mathrm{l}$ each) was added to the wells. The plate was left at room temperature for $24 \mathrm{~h}$. Controls were prepared by omitting tyrosinase. (2) Samples $(0.5 \mathrm{ml}$ each) containing 5.4 $\mathrm{mU} / \mathrm{ml}$ tyrosinase and $10 \mu \mathrm{M} 2$ and/or $10 \mu \mathrm{M}$ DOPA or none of them were preincubated at $37^{\circ} \mathrm{C}$ for $0,3,10,30$, or $60 \mathrm{~min}$ and then the enzyme was assayed by adding $0.5 \mathrm{ml}$ prewarmed $\left(37^{\circ} \mathrm{C}\right)$ solutions of $5 \mathrm{~mm}$ DOPA. (3) Samples $(0.5 \mathrm{ml}$ each $)$ containing $5.4 \mathrm{mU} / \mathrm{ml}$ tyrosinase and $0-10 \mu \mathrm{M} 2$ and $0-2500 \mu \mathrm{M}$ DOPA were preincubated at $37^{\circ} \mathrm{C}$ for $10 \mathrm{~min}$ and then the enzyme was assayed by adding $0.5 \mathrm{ml} 5 \mathrm{~mm}$ DOPA. (4) Samples (10 $\mu \mathrm{l} \mathrm{each)}$ containing $5.4 \mathrm{mU} / \mathrm{ml}$ tyrosinase $(20 \mu \mathrm{g}$ total protein), $0-10 \mu \mathrm{M} 2$ (added as $1 \mu \mathrm{l}$ ethanol solution), and $0-2500 \mu \mathrm{M}$ DOPA were incubated at $37^{\circ} \mathrm{C}$ for $1 \mathrm{~h}$ and then mixed with $10 \mu \mathrm{l}$ loading buffer (4\% sodium dodecyl sulfate, $20 \%$ glycerol and $0.02 \%$ Bromophenol blue in $0.1 \mathrm{M}$ Tris/ $\mathrm{HCl}$ buffer, $\mathrm{pH}$ 6.8). The mixtures (10 $\mu \mathrm{l}$ each) were immediately applied to a $10-20 \%$ density gradient polyacrylamide gel and electrophoresed under the condition of $\mathrm{Laemmli}^{26)}$ at $4{ }^{\circ} \mathrm{C}$ for $80 \mathrm{~min}$. The gel was immersed in $30 \mathrm{ml} 50 \mathrm{~mm}$ phosphate buffer ( $\mathrm{pH}$ 6.8) containing $1.5 \mathrm{~mm}$ DOPA and $4 \mathrm{~mm} 3$-methyl-2benzothiazolinone hydrazone at $37^{\circ} \mathrm{C}$ for $2 \mathrm{~h}$. The coloration was recorded by a scanner, and then the gel was stained with Coomassie brilliant blue. Another gel containing electrophoresed tyrosinase was treated for Western blot analysis by the usual method with anti-tyrosinase C-19 goat immunoglobulin G (IgG) (Santa Cruz Biotechnology Inc., Santa Cruz, CA, U.S.A.) and horseradish peroxidase rabbit anti-goat $\operatorname{IgG}(\mathrm{H}+\mathrm{L})$ conjugate (Zymed Laboratories Inc., San Francisco, CA, U.S.A.).

Inhibitor Removal by Gel Permeation Chromatography Samples ( $1 \mathrm{ml}$ each) containing $2.7 \mathrm{mU} / \mathrm{ml}$ tyrosinase, $0.05 \% \mathrm{NP}-40$ (derived from the enzyme extract), and $10 \mu \mathrm{M} 2$ plus $10 \mu \mathrm{M}$ DOPA, $10 \mu \mathrm{M} 2$ alone, $10 \mu \mathrm{M}$ DOPA alone, or none of them in $47 \mathrm{~mm}$ phosphate buffer $(\mathrm{pH} 6.8$ ) were prepared and incubated at $37^{\circ} \mathrm{C}$ for $1 \mathrm{~h}$. Then, $12.5 \mathrm{~mm}$ DOPA in $50 \mathrm{~mm}$ phosphate buffer ( $\mathrm{pH} 6.8)(0.25 \mathrm{ml}$ each) was added to the pretreated mixtures and absorbance at $475 \mathrm{~nm}$ was continuously recorded at $24^{\circ} \mathrm{C}$. On the other hand, the same samples as above were incubated at $37^{\circ} \mathrm{C}$ for $1 \mathrm{~h}$, and then applied to a Sephadex ${ }^{\circledR}$ G-50 column $\left(10 \mathrm{~cm}^{3}\right)$ equilibrated with $50 \mathrm{~mm}$ phosphate buffer ( $\mathrm{pH} 6.8$ ) containing $0.05 \%$ NP-40. Elution was performed with the same buffer and the eluate was divided into 1-ml fractions. Proteins were eluted in Fr. 4 and 5, while 2 and DOPA were eluted in Fr. 9-16 as evidenced by UV monitoring at $280 \mathrm{~nm}$. From the combined solution of Fr. 4 and 5 , aliquots $(0.8 \mathrm{ml}$ each) were taken and mixed with $0.2 \mathrm{ml} 12.5 \mathrm{~mm}$ DOPA to assay tyrosinase activity. The same experiment was repeated with the sample for 2 plus DOPA, but the eluate from the column was left at room temperature for $6 \mathrm{~h}$ before initiating the assay as above.

\section{References}

1) Chang T.-S., Int. J. Mol. Sci., 10, 2440-2475 (2009)

2) Nesterov A., Zhao J., Minter D., Hertel C., Ma W., Abeysinghe P., Hong M., Jia Q., Chem. Pharm. Bull., 56, 1292-1296 (2008).

3) Nakashima S., Matsuda H., Oda Y., Nakamura S., Xu F., Yoshikawa M., Bioorg. Med. Chem., 18, 2337-2345 (2010).

4) Seo W. D., Ryu Y. B., Curtis-Long M. J., Lee C. W., Ryu H. W., Jang K. C., Park K. H., Eur. J. Med. Chem., 45, 2010-2017 (2010).

5) Yamazaki Y., Kawano Y., Yamanaka A., Maruyama S., Bioorg. Med. Chem. Lett., 19, 4178-4182 (2009).

6) Yamazaki Y., Kawano Y., Z. Naturforsch., 65c, 49-54 (2010).

7) Park J. B., Chen P., J. Chromatogr. B, 852, 398-402 (2007).

8) Cho S. J., Roh J. S., Sun W. S., Kim S. H., Park K. D., Bioorg. Med. Chem. Lett., 16, 2682-2684 (2006).

9) Wang K.-H., Lin R.-D., Hsu F.-L., Huang Y.-H., Chang H.-C., Huang C.-Y., Lee M.-H., J. Ethnopharmacol., 106, 353-359 (2006).

10) Jin Y. H., Lee S. J., Chung M. H., Park J. H., Park Y. I., Cho T. H., Lee S. K., Arch. Pharm. Res., 22, 232-236 (1999).

11) Takara K., Iwasaki H., Ujihara K., Wada K., J. Oleo Sci., 57, 191196 (2008)

12) Kanehira T., Takekoshi S., Nagata H., Osamura R. Y., Homma T., Planta Med., 69, 457-459 (2003).

13) Shin N.-H., Ryu S. Y., Choi E. J., Kang S.-H., Chang I.-M., Min K. R., Kim Y., Biochem. Biophys. Res. Commun., 243, 801-803 (1998).

14) Dixon M., Webb, E.C., "Enzymes," 3rd ed., Longman Group, London, 1979, pp. 339-341, 349

15) Olivares C., Jiménez-Cervantes C., Lozano J. A., Solano F., GarcíaBorrón J. C., Biochem. J., 354, 131-139 (2001).

16) Kwon B. S., Haq A. K., Pomerantz S. H., Halban, R., Proc. Natl. Acad. Sci. U.S.A., 84, 7473-7477 (1987).

17) Tomita Y., Hariu A., Mizuno C., Seiji M., J. Invest. Dermatol., 75 , 379-382 (1980)

18) Muñoz-Muñoz J. L., Acosta-Motos J. R., Garcia-Molina F., Varon R., Garcia-Ruíz P. A., Tudela J., García-Cánovas F., Rodríguez-López J. N., Biochim. Biophys. Acta, 1804, 1467-1475 (2010).

19) Muñoz-Muñoz J. L., García-Molina F., García-Ruiz P. A., MolinaAlarcón M., Tudela J., García-Cánovas F., Rodríguez-López J. N., Biochem. J., 416, 431—440 (2008).

20) Chang T.-S., J. Agric. Food Chem., 55, 2010-2015 (2007).

21) Land E. J., Ramsden C. A., Riley P. A., Tohoku J. Exp. Med., 212, $341-348$ (2007)

22) Ramsden C. A., Stratford M. R. L., Riley P. A., Org. Biomol. Chem., 7, 3388-3390 (2009)

23) García-Molina F., Hiner A. N. P., Fenoll L. G., Rodríguez-Lopez J. N., García-Ruiz P. A., García-Cánovas F., Tudela J., J. Agric. Food Chem., 53, 3702-3709 (2005).

24) Chen Q.-X., Huang H., Kubo I., J. Protein Chem., 22, 481-487 (2003).

25) Qiu L., Chen Q.-X., Wang Q., Huang H., Song K.-K., Bioorg. Med. Chem., 13, 6206-6211 (2005).

26) Laemmli U. K., Nature (London), 227, 680-685 (1970). 